\title{
Chimalpahin, su formación y sus noticias sobre la presencia de la Iglesia Católica en Chalco Amaquemecan, siglos XVI-XVII
}

\author{
Clementina Battcock*
}

Recibido el 4 de diciembre de 2018; aceptado el 22 de marzo de 2019

\section{RESUMEN}

El presente artículo se propone analizar la información sobre el proceso de evangelización contenida en las obras de Domingo de San Antón Muñón Chimalpahin Cuauhtlehuanitzin — su Diario y sus Relaciones - a la luz de los antecedentes y la formación de su autor. Por su condición de noble, y educado a la vera de la Iglesia Católica, Chimalpahin intentó insertar el pasado de los chalcas en la gran historia salvífica regida por la Providencia. De ahí la importancia de aproximarse a su etapa formativa y al análisis de sus relaciones sociales.

Palabras clave: Chimalpahin, Chalco-Amaquemecan, Iglesia Católica, Diario, Relaciones.

\section{Chimalpahin, His Upbringing and His News about the presence of the Catholic Church in Chalco Amaquemecan, XVI-XVII centuries}

\section{AbSTRACT}

The present paper delves into the information about the process of evangelization contained in the works of Domingo de San Antón Muñón Chimalpa-

* Instituto Nacional de Antropología e Historia, Secretaría de Cultura, Gobierno de México, Ciudad de México, México, correo electrónico: cbattock.deh@inah.gob.mx 
hin Cuauhtlehuanitzin - his Journal and his Relations - in the light of the author's background and upbringing. Because of his status as a nobleman raised by the Catholic Church, Chimalpahin tried to insert the past of the Chalcas into the great scheme of the history of salvation. Hence the importance of approaching his formative stage and the analysis of their social relations.

Key words: Chimalpahin, Chalco-Amaquemecan, Catholic Church, Diario, Relaciones.

\section{LOS INICIOS DE LA EVANGELIZACIÓN EN CHALCO}

$\mathrm{U}$ na vez concluida la guerra de conquista contra Tenochtitlan, los conquistadores castellanos iniciaron un complejo e irregular proceso de evangelización en las poblaciones próximas a la Cuenca de México. Según los escritos del propio Hernán Cortés, y luego secundado por Bernal Díaz del Castillo, la incursión de frailes católicos para la región de Chalco inició con las prédicas de fray Bartolomé de Olmedo, ${ }^{1}$ a lo que siguió la quema y destrucción de los teocallis de Amecamecan, Tlamanalco y Tenango. ${ }^{2}$

La Orden de los Frailes Menores de San Francisco inició su presencia en Chalco a partir de 1524, y con ello estableció una red de relaciones que se articuló a los principales centros políticos de la región, pues desde 1531 se estableció una doctrina franciscana en Tlalmanalco, y la existencia de un doctrinero fijo de esta orden en Santiago de Chalco se documentó en 1558, relaciones que se verían impactadas tras la llegada de otras órdenes como la de Santo Domingo, que ocuparon casa en Asunción Amaquemecan desde $1550 .^{3}$

Todo este proceso de cambio fue narrado muchas décadas después por una peculiar pluma: la de Domingo de San Antón Muñón Chimalpahin Cuautlehuanitzin, cronista nahua que nació en Tzacualtitlan Tenanco Chiconcohuac, barrio-cabecera de la localidad de Chalco Amaquemecan, uno de los cuatro pueblos de la provincia chalca del siglo XVI (véase Mapa 1). ${ }^{4}$

1 Ricard, La conquista espiritual de México. Ensayo sobre el apostolado y los métodos misioneros de las órdenes mendicantes en la Nueva España de 1523-1524 a 1572, p. 80.

Vid Jarquín y Carlos Herrejón, Breve historia del Estado de México.

Gerhard, Geografia histórica de la Nueva España 1519-1821, p. 106.

4 Jalpa, Tierra y sociedad. La apropiación del suelo de la región de Chalco durante los siglos $X V$-XVIII. Para una revisión de los grupos sociales asentados en esos territorios y sus vinculaciones mítico-sagradas, vid. Durand-Forest, "Los grupos chalcas y sus divinidades según Chimalpahin", pp. 37-44. 


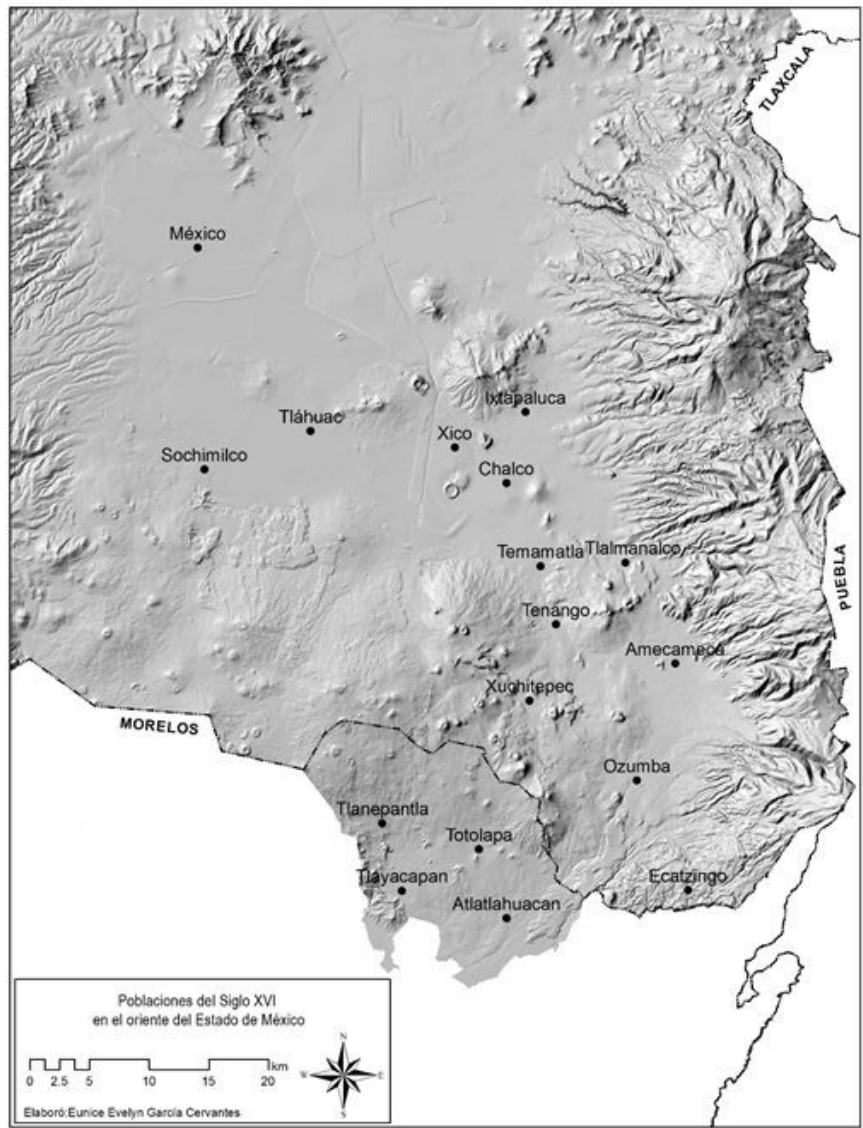

Mapa 1. Poblaciones del siglo XVI en el oriente del Estado de México. ${ }^{5}$

\section{Algunas NOTAS BIOGRÁFICAS SOBRE CHIMALPAHIN}

Mucho se ha afirmado que vino al mundo el martes 26 de mayo de 1579 , pero en un apunte de su Séptima Relación de ese año, y hablando en tercera persona, él mismo asevera:

5 Agradezco al arqueólogo Luis Antonio Huitrón Santoyo, a la licenciada Daniela Tovar del Centro INAH del Estado de México, y a la arqueóloga Eunice Evelyn García Cervantes del Centro INAH Estado de México, por la elaboración de este mapa. 


\begin{abstract}
Al amanecer del miércoles 27 del mes de mayo, cuando habían pasado seis días del amor a sí mismo que se dice signo de géminis, entonces nació el mencionado Domingo de San Antón. ${ }^{6}$

En las vísperas de nuestro Señor Jesucristo, la que se dice fiesta de la Ascensión, cuando se dignó a subir por sí mismo al cielo, nació Domingo Francisco de San Antón Chimalpahin Cuauhtlehuanitzin, nieto en la novena línea del muy fuerte y valiente Chichimécatl Cuauhtlehuanitzin, tlailotlacteuctli, que venía fungiendo como el total gobernante y guía de los tenanca cuixcoca temimilolca ihuapanenca zacanca. ${ }^{7}$
\end{abstract}

La precisión del señalamiento de fechas y calendarios no era ninguna extravagancia personal. Chimalpahin era hijo de su tiempo: para los hombres de entonces, la escritura de diarios, crónicas y relatos sobre sus propios orígenes se inscribían en contextos de movimientos siderales e influencias astrológicas, pero también en el plano de la cobertura espiritual, mediante la protección de algún santo patrón del calendario litúrgico. El objetivo era ubicar al alma y al cuerpo en la geometría divina, sometida a regularidades mesurables desde su ubicación terrenal. En dicho espíritu, otros cronistas novohispanos también trazaron milimétricamente las líneas de su estirpe indígena como prueba de legitimidad y de sus méritos políticos. ${ }^{8}$

Domingo Francisco mismo dejó datos sobre su cepa familiar y lo hizo con gran orgullo: era tataranieto por línea paterna de Huehue Chimalpahitzin Mocahuqui; por línea materna descendía de Huehue Cuauhtlehuanitzin Tlailotlaceutli. Su abuelo materno fue Domingo Hernández Ayopochtzin, casado con Marta de Santiago Amaxochtzin, quienes, además de una hija, tuvieron otros dos vástagos: Diego José Hernández y Cristóbal de Castañeda. ${ }^{9}$ Este último llegaría a ser gobernador de Amaquemecan, así que el linaje de Domingo Francisco era, sin discusión, de nobles y principales.

El padre de Chimalpahin, Juan Agustín Ixpintzin, y su madre María Jerónima Xiauhtotzin, criaron a Domingo Francisco en su hogar, donde fue instruido en la lengua nahuatl y en las antiguas historias, a través de la lectura y memorización de signos pintados en los códices, lo que con el tiempo le permitiría hacer una interpretación más amplia del pensamiento indígena. Pasó luego, todavía muy niño, al convento de Nuestra Señora de la Asunción de su localidad, en el que los frailes residentes le enseñaron la doctrina y a

Chimalpahin Cuauhtlehuanitzin, Séptima relación de las Différentes Histoires Originales, p. 313.

Ibid.

Otros dos cronistas que dejaron registros similares de los linajes de origen indígena en el contexto novohispano: Hernando Alvarado Tezozómoc y Fernando de Alva Ixtlilxóchitl. Vid. Alvarado Tezozómoc, Crónica mexicana, e Ixtlilxóchitl, Obras históricas. Sobre ellos y la historiografía de tradición indígena, véase, José Rubén Romero Galván (coord.), Historiografia mexicana, vol. I, Historiografia novohispana de tradición indígena.

9 Datos de su genealogía en: Chimalpahin, Diario y Séptima relación, p. 208, 218-219, 235, 239. 
leer y escribir, ${ }^{10}$ en consonancia con la formación que se daba a los jóvenes de la nobleza indígena.

Por un pasaje del preámbulo que el propio Chimalpahin escribió a su Octava Relación y a su Diario se entiende que en algún momento de su infancia se trasladó a la Ciudad de México para continuar con su educación, ${ }^{11}$ aunque se desconoce el sitio preciso donde fue a prepararse. Difícilmente pudo ser el Colegio de la Santa Cruz de Tlatelolco - como lo creen Durand-Forest y Ángel María Garibay- ${ }^{12}$ que estaba involucionando ya por entonces a escuela de primeras letras. En el Colegio de San Gregorio, fundado en 1586, la Compañía de Jesús daba formación superior a los hijos de los caciques y principales. En ningún caso, empero, hay datos fehacientes de que Domingo Francisco haya acudido a clases a uno o a otro. De hecho, Susan Schroeder cree que no recibió ningún tipo de educación secundaria y asume que incluso la lecto-escritura la aprendió sirviendo en la ermita San Antonio. ${ }^{13}$ Esto es sumamente dudoso; el que Chimalpahin conociera y luego utilizara en sus escritos a Platón, Aristóteles, Sófocles, Diógenes, San Agustín y Santo Tomás de Aquino difícilmente puede explicarse a partir de la mera instrucción elemental que hubiera podido recibir de un presbítero cualquiera en una ermita. Mucho más probable es, a mi juicio, que Domingo hubiera asistido a algún colegio franciscano o, mejor aún, al jesuita, aunque fuese por pocos años y que ahí hubiera adquirido el conocimiento de los referidos autores clásicos y cristianos.

En cambio, hay certezas de que, al cumplir los catorce años, Chimalpahin entró a servir en la mencionada ermita de San Antonio Abad y que ahí inició una profunda y reflexiva inmersión en el mundo cristiano. ${ }^{14}$ Vale la pena dedicar unas cuantas palabras a dicho templo. Ubicado en las goteras de la ciudad de México, había sido una fundación de 1530 promovida por un vecino llamado Alonso Sánchez, a quien el cabildo le concedió un predio en la punta de una isleta y sobre la calzada que iba a Iztapalapa. Allí, a su costa, construyó una ermita en honor de San Antonio Abad, o ermitaño. ${ }^{15}$ Esta área, en el vecindario indígena de Xolloco-Acatla, pertenecía a la doctrina franciscana de San Pablo, pero estuvo secularizada entre 1565 y 1574 y justamente en ese período se emprendió la restauración del inmueble. En

10 Romero Galván, “Chimalpahin...”, op. cit., p. 331.

11 Chimalpahin, Octava ..., op. cit., p. 73.

12 Durand-Forest, L'histoire de la vallée de Mexico selon Chimalpahin Quauhtlehuanitzin (du XI au XVI siecle), p. 56; Garibay, Historia de la literatura náhuatl, p. 727.

13 Schroeder, "Introduction", Códex Chimalpahin. Society and Politics in Mexico Tenochtitlan, Tlatelolco, Texcoco, Culhuacan, and other nahua altepetl in central Mexico, p. 13.

14 Así lo informa Chimalpahin en su Diario, op. cit.; Cfr. Romero, "Prólogo", pp. 12, 13, 24.

15 Marroquí, La ciudad de México, vol. I, pp. 432-433. 
1562, Claudio Arciniega, maestro de obras de la catedral, y don Sancho Sánchez de Muñón, acaso pariente del fundador, pero sin duda, maestrescuela del Colegio Catedralicio y cancelario de la Universidad tomaron a su cargo la obra. En el templo restaurado se fundó el 19 de enero de 1565 una cofradía de españoles y los indígenas del barrio colaboraron con entusiasmo fabricándole a la hermandad imágenes del santo. A partir de 1568, San Antonio Abad fue considerada ermita sufragánea al distrito parroquial catedralicio, ${ }^{16}$ era atendida, pues, por el clero secular.

Tal debió ser la condición de San Antonio Abad cuando Chimalpahin llegó a ese templo hacia 1593, siendo un adolescente. Bien pudo haber empezado desempeñando ahí oficios simples y modestos, como monaguillo o encargado del aseo, antes de convertirse en sacristán o de recibir responsabilidades mayores en el cuidado del inmueble o la atención del culto, hasta que alcanzó la categoría de mayoral, como autoridad indígena superior en una iglesia. ${ }^{17}$

Es muy probable que Chimalpahin comenzara a escribir después de 1606, cuando murió su padre y éste le entregó algunos manuscritos genealógicos en náhuatl, mismos que fueron compilados por su suegro, abuelo materno de Chimalpahin, el ya mencionado Domingo Hernández Ayopochtzin, que junto al nombre de su protector, el también mencionado Sancho Sánchez de Muñón, dejaron huella en el apelativo que el cronista chalca utilizó definitivamente a partir de 1613: Don Domingo de San Antón Muñón, recalcando con él su sentido de pertenencia a la nobleza indígena. ${ }^{18}$

Ya con poco más de cuarenta años, aproximadamente en 1620 Chimalpahin decidió no sólo ejercer tareas menestrales, sino empezar a escribir también sobre materias históricas. Se piensa que sirvió más de 20 años en la ermita - 26 en concreto - y hay quien cree que ahí permaneció toda su vida. Lo más probable es que la llegada de los canónigos regulares de San Antonio a México haya cambiado su destino porque éstos solicitaron y obtuvieron la ermita de San Antonio Abad para establecer su priorato y hospital, ${ }^{19}$ dedicado a atender enfermos, al parecer de lepra, pero también de otros males de la piel. ${ }^{20}$

Rovira Morgado, "Barrios indígenas virreinales como espacios de salvaguardia y legitimación franciscanas".

17 Martínez Baracs, "El diario de Chimalpáhin”, pp. 289-290.

18 Ibid.

19 Rivera Cambas, México pintoresco, artístico y monumental, vol. I, p. 188.

20 Fundada en Francia en el siglo XI, la corporación religiosa tuvo por finalidad la atención de las víctimas del llamado "fuego de San Antonio", un mal, causado por un hongo del centeno, que podía atacar las vísceras ocasionando una muerte inmediata; o infectar los miembros, que acababan por tullirse o gangrenarse. Su propagación en Europa llegó a alcanzar 
Tal vez entonces los servicios de Chimalpahin en San Antonio se volvieron innecesarios y quizá se buscó otra ocupación y otra residencia; acaso volvió a Amaquemecan, a entrevistarse con algunos de sus informantes o preservadores de las antiguas memorias. O se alojó en otras iglesias de México, donde pudiera desempeñar las actividades de "mayoral" que conocía a la perfección. A partir de estos años, la década de los treinta del siglo XVII, nada se sabe de él. Parece que murió ya mediado el siglo. Todo en esta etapa final de su vida es obscuridad.

\section{LA EVANGELIZACIÓN EN CHALCO AMAQUEMECAN, SEGÚN CHIMALPAHIN}

Chimalpahin preservó notas sobre esta época en sus manuscritos — su Diario y sus ocho Relaciones, denominadas posteriormente Différentes Histoires Originales $-{ }^{21}$ que dan algunas luces sobre la configuración política, social y religiosa de su estrato social: la nobleza indígena venida a menos tras la conquista. ${ }^{22}$ Para Susan Schroeder un aspecto fundamental en el análisis de la obra de Chimalpahin es su perfil como indígena cristiano, y por este sentido identitario en sus escritos las prácticas rituales indígenas se describen como atrocidades. Aun cuando su sólida educación que recibió entre su gente le daba acceso a los conocimientos nahuas, Chimalpahin nun-

niveles epidémicos y, para curarse, los enfermos solían peregrinar a los santuarios de San Antonio el Ermitaño. Ahí rezaban y eran atendidos por los hermanos antoninos. El nombre actual de la enfermedad es "ergotismo". Vid Laval, "Sobre las epidemias del fuego de San Antonio", pp. 74-76; García Cubas, El libro de mis recuerdos: narraciones históricas, anecdóticas y costumbres mexicanas anteriores al actual estado social, ilustradas con más de trescientos fotograbados, pp. 130-131.

21 Los estudios que abrieron camino a la formulación de nuevos postulados sobre las obras de este cronista fueron las ediciones de la Octava y de la Tercera Relación, de José Rubén Romero Galván en 1983 y de Víctor Manuel Castillo Fareras en 1997, respectivamente. Cfr. Chimalpahin Cuauhtlehuanitzin, Octava relación. Obra histórica, 1983; Chimalpahin Cuauhtlehuanitzin, Octava relación. Obra histórica y Chimalpahin Cuauhtlehuanitzin, Primer amoxtli libro. $3^{a}$ Relación de las Différentes Histoires Originales, 1997. La edición de mayor consulta de los manuscritos de Chimalpahin es la de Rafael Tena (1998), que agrupa las denominadas Ocho relaciones y el memorial de Colhuacan. Más tarde, Tena tradujo el Diario del cronista indígena virreinal en 2001. Vid. Chimalpáhin, Las ocho relaciones y el memorial de Colhuacan, y Chimalpáhin, Diario.

22 Vid. Durand-Forest, "Extractos de la Primera relación de Chimalpahin Quauhtlehuanitzin (Manuscrito $\mathrm{N}^{\circ} 74$ de la Colección Goupil-Aubin de la Biblioteca Nacional de París, folios 1 a 8 verso), pp. 65-76; Romero Galván, "Chimalpahin Cuauhtlehuanitzin”, pp. 331-350. Asimismo, son interesantes las precisiones sobre la relación entre los textos de Chimalpahin y otro cronista indígena novohispano, Hernando Alvarado Tezozomoc, relación inscrita en la Crónica mexicáyotl. Al respecto cfr. Kruell, "La Crónica mexicáyotl: versiones coloniales de una tradición histórica mexica tenochca”, pp. 197-292. 
ca perdió de vista su objetivo: las relaciones con el territorio y con la noción de una historia cristiana que cubre todos los aspectos de la existencia humana, sea cual sea su ubicación espacial o temporal. ${ }^{23}$

Sobre su historia, Serge Gruzinski apunta:

Sus Relaciones son relatos indígenas que, apoyados en los códices prehispánicos y coloniales, abordan por turno emigraciones, conquistas, alianzas y genealogías. Pero Chimalpahin, que también explota fuentes europeas, posee una manera muy suya de insertar la historia del señorío de ChalcoAmecameca - lo local, según nuestro cronista - en la perspectiva de la mundialización ibérica y de leer ésta a partir de la ciudad de México. Este paso es el que da toda la ambigüedad y todo su interés al memorialista chalca. Para conectar los mundos Chimalpahin saquea el Repertorio de los tiempos, de Heinrich Martin (1606). ${ }^{24}$

La historia narrada por Chimalpahin de una cristiandad católica del siglo XVI en Chalco Amaquemecan está salpicada de varios episodios e hitos puntuales, los cuales responden a un contexto de honda transformación cultural en el que los antiguos valores indígenas se encuadraron en un nuevo marco teleológico de negociación de la espiritualidad, de las costumbres y de las relaciones de poder. ${ }^{25}$

Cabe señalar que los franciscanos se encargaron desde fechas tempranas de la evangelización de Amaquemecan. En 1525 quemaron y destruyeron los adoratorios y templos-teocalli de los naturales e impartieron el bautismo en masa, y en 1529 instruyeron los primeros matrimonios monógamos entre los indios principales. ${ }^{26}$ Sin embargo, la llegada de fray Martín de Valencia a la zona, en 1531, produjo el más penetrante y trascendental impacto entre los amaquemeque: se ganó el favor del importante y preeminente señor en el tlayácatl de Itztlacozauhcan, don Tomás de San Martín Quetzalmazatzin, quien promovió la erección de la primera ermita cristiana en la población: la de Santo Tomás Apóstol. Al tiempo, fray Martín que tenía señalada inclinación por los ejercicios de eremitismo y ascetismo de tradición paleocristiana fue haciendo retiros rutinarios a las cuevas del Amaqueme. ${ }^{27}$

Paradójicamente, en el cerro se recreaba un espacio sagrado de un ritual político, que pudo ser visto como un acto de merecimiento indígena (en náhuatl tlamacehualiztli), conectado con el culto a un avatar zoomórfico del 
solitario y penitente dios Tezcatlipoca. Así, la fama de este nuevo ixiptla, una personificación del célebre "Señor del Espejo Humeante" -metamorfoseado en un solitario sacerdote franciscano, de apariencia miserable, con "andrajos sucios y pies agrietados", y que sólo comía al mediodía "mole de guajolote"- ${ }^{28}$ constituyó una sólida fuente de legitimación de poder para las autoridades del altepetl y república de yndios de Chalco Amaquemecan a lo largo del siglo XVI. A este fraile se le imaginó como un símbolo, hasta el punto de que en 1583 se le labró un sepulcro conmemorativo en el Amaqueme para honra de los célebres ayunos y penitencias del santificado fray Martín de Valencia, años después de que los religiosos seráficos hubiesen abandonado esta localidad. ${ }^{29}$

A pesar de la extraordinaria trascendencia que los actos del padre Valencia estaban destinados a ocupar en el imaginario religioso y político de las élites de los amaquemeque, lo cierto es que la orden de San Francisco abandonó súbitamente la ermita de Santo Tomás Apóstol en Itztlacozauhcan en el año 1537. Según el propio Chimalpahin, la desafección de los seráficos en Amaquemecan se produjo a raíz de la llegada de varios frailes dominicos al tlayacatl de Tlailotlacan, dominado por don Juan de Sandoval Tecuanxayacatzin. Este señor, como sucedió con infinidad de linajes indígenas y europeos, se habría enemistado con su hermano Quetzalmazatzin del tlayacatl de Itztlacozauhcan $-\mathrm{y}$, por ende, con toda la red social y clientelar que éste controlaba-, y ayudó a los dominicos, tanto en la construcción de una nueva ermita dedicada a san Juan Evangelista en Tlailotlacan, como con la transferencia de mano de obra indígena para las obras del convento de Santo Domingo de México. ${ }^{30}$ Este suceso resulta altamente sugerente para comprender hasta qué grado el faccionalismo regional, presente entre las élites nativas (de evidente raíz prehispánica), continuó con fuerza tras la Conquista, y cómo los nuevos interlocutores espirituales cristianos de los señores y los principales fueron insertados, consciente e interesadamente, en dichas dinámicas sociopolíticas conflictivas.

El propio Chimalpahin tuvo a bien recordar que el asiento definitivo de la orden de los Predicadores en Amaquemecan se produjo entre los años 1547 y 1554 . Pues en 1547 falleció Quetzalmazatzin y se iniciaron las obras de edificación del convento e iglesia parroquial de Nuestra Señora de la Asunción; en 1550 los dominicos fijaron su residencia en San Juan Evangelista Tlailotlacan y, finalmente, en 1554, se efectuó la inauguración del con- 
vento dominico de la localidad. ${ }^{31}$ Seis años más tarde se dio un paso definitivo hacia la plena constitución de la naturaleza jurídica que tendría este centro chalca en el virreinato temprano con la aparición de la gobernación concejil y cabildo indio (1560), ${ }^{32}$ suceso político que estuvo convenientemente acolchado por las gratificaciones y expectativas de los religiosos dominicos. Y es que resulta destacable que, en 1561, el primer gobernador de la república de yndios de Chalco Amaquemecan fue precisamente don Juan de Sandoval Tecuanxayacatzin, señor del tlayácatl de Tlailotlacan. ${ }^{33}$

\section{LAS RELACIONES SOCIALES DE CHIMALPAHIN}

Aquí vale la pena trazar una parábola y, teniendo presente la información presentada en torno a la evangelización en Chalco, volver a la formación de Chimalpahin, pero ahora vista a la luz de las relaciones sociales que estableció el cronista chalca.

Chimalpahin, quizás enorgulleciéndose y haciendo alarde de su antiguo abolengo tenanca, no dejó pasar la oportunidad de registrar que la gobernación en Amaquemecan se volvió inmediatamente rotativa a partir de 1563, y que el resto de tlayacatl de Itztlacozauhcan, Tzacualtitlan Tenanco, Tecuanipan y Panohuayan pudo enviar a sus respectivos señores y principales para que participasen en ella cada cuatro años. ${ }^{34} \mathrm{La}$ implicación progresiva de las autoridades de estos barrios-cabeceras de los amecameque en la gobernación, alcaldías y regidurías de su cabildo indio, pudo constituir un fuerte detonante para que las nuevas identidades vecinales se afianzasen a la sombra de la edificación, a lo largo del año 1576, de las iglesias de Santiago en Tzacualtitlan Tenanco y de San Felipe en Panohuayan. ${ }^{35}$

En este contexto, la educación del niño Domingo Francisco, nacido tres años después, se esmeraría en asegurar el nuevo legado a través del orgullo inculcado del linaje propio. Es probable que Chimalpahin adquiriese parte de su educación en el tecpan familiar de Tzacualtitlan Tenanco, y que también participase en el cuidado, acicalamiento y celebración de festividades relacionadas con la parroquia vecinal consagrada al apóstol Santiago.

Por su condición de pilli, debió acudir de forma rutinaria al convento de Nuestra Señora de la Asunción de Amaquemecan, y tampoco parece impro-

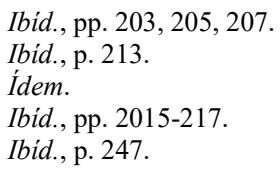


bable plantear que, antes de ir a la Ciudad de México — donde, ya se dijo, al cumplir los catorce años ingresó a la ermita de San Antonio Abad-, pudiese haber llegado a visitar y a recibir instrucción docente y espiritual en el resto de los conventos que configuraban la malla dominica afincada en la falda de los volcanes Iztaccíhuatl y Popocatépetl, como las casas de Chimalhuacan y de Tetela.

Con todo, continúa siendo una incógnita los motivos que promovieron su entrada en 1593 a la ermita de San Antonio Abad, en la parcialidad de San Pablo de México. Sin embargo, es necesario traer a colación que, para esas fechas, entre los siglos XVI y XVII, doña Martina y don Nicolás Hernández Tlacaelleltzin - madre e hijo, y descendientes del antiguo y afamado cihuacoatl Tlacaelel - constituían la cabeza visible de una prestigiosa feligresía indígena afincada en los adyacentes barrios tenochcas de Ateponazco y Xolloco Acatla, y que sería adepta y devota del cercano San Antonio Abad. ${ }^{36}$

Las reflexiones que Susan Schroeder elabora en torno a la presencia de la figura de Tlacaélel como un sujeto clave en la dinámica política de la configuración del dominio tenochca en la Cuenca de México, ciertamente inscrita en la narrativa de los textos de Chimalpahin, ${ }^{37}$ me motivan a postular que quizá la ubicación de Chimalpahin en esta ermita de San Antonio pudo estar relacionada con las viejas conexiones genealógicas que el linaje del cihuacoatl Tlacaelel, de México-Tenochtitlan, mantuvo con las autoridades de varios tlayacatl de Chalco Amaquemecan desde tiempos más antiguos que el florecimiento tenochca. Me atrevo a conjeturar que un buen conocido de Chimalpahin fue un posible hijo de don Nicolás Hernández Tlacaelleltzin, de nombre Francisco Hernández, sujeto que fue registrado en las notas y declaraciones administrativas relacionadas con la gran inundación que padeció la ciudad de México en 1629, pues Francisco Hernández era un vecino del barrio de San Antonio Abad en 1630, además de ser un acreditado como informante indígena del pasado prehispánico y un notable poseedor de pinturas antiguas. ${ }^{38}$

Al mantenerse vigentes las citadas relaciones de parentesco a lo largo del virreinato, seguramente facilitaron el desplazamiento de indígenas relacionados entre sí por pactos políticos y familiares remotos. Es decir, algunos cristianos de la nobleza india novohispana abandonaron, en su juventud, su hogar nahua para instruirse y prestar servicios en los nuevos centros espiri-

36 Chimalpahin, Annals of his time. Don Domingo de San Antón Muñón Chimalpahin Quauhtlehuanitzin, pp. 155, 172, 239.

37 Schroeder, Tlacaelel remembered. Mastermind of the Aztec Empire.

38 Orozco y Berra, Apuntes para la historia de la geografía en México, p. 146. 
tuales urbanos de la ciudad de México, en los que además de sus tareas cotidianas, sus miembros realizaron notables ejercicios intelectuales, sostenidos o apoyados por las relaciones interpersonales que les permitieron concretar esa movilidad y sustentar su supervivencia, tal y como fue el caso de Chimalpahin con su protector, Sancho Sánchez de Muñón. ${ }^{39}$

\section{CONSIDERACIONES FINALES}

Domingo Francisco Chimalpahin intentó resolver diversos problemas de orden simbólico, como ubicarse en la historia de la redención, regida por la Providencia, en tanto descendiente de los antiguos pobladores de un Nuevo Mundo aislado del resto de la Ecúmene. Esto equivalía a encontrar, para él mismo y para los demás indígenas, un lugar en esa historia de Salvación en la que sólo tenían cabida los descendientes de Adán y Eva. Su labor historiográfica tenía como objetivo resolver sus registros prehispánicos con la mirada fija en la historia sagrada. ${ }^{40}$

Este texto profundiza sobre los procesos que Chimalpahin retomó para explicar las condiciones históricas de Chalco Amaquemecan, espacio que tuvo un largo y complejo camino en su relación cultural con las instituciones de gobierno virreinales. Sin embargo, la relación de otras notas, y su correspondencia con los elementos narrativos que plantea Chimalpahin, me permiten proponer y conjeturar una explicación sobre las estrategias que los actores siguieron durante la reconfiguración política y social de los territorios de la cuenca de México.

En suma, Chimalpahin se propuso buscar afanosamente el vínculo que le permitiera a él y a los suyos incluirse en la Redención. Su obra es prueba de que en su tiempo hubo hombres indígenas que no escatimaron esfuerzos a fin de vincularse con aquella historia, la única posible por el horizonte cristiano. Con ese objetivo, para este cronista, era imperante ubicar su trabajo en relación con la historia de la creación divina. Y para fundamentar sus argumentos le fue menesteroso apoyarse en autoridades históricas legitimadas por la tradición cristiana occidental, tales como los Padres de la Iglesia Católica Romana, y los filósofos de la antigüedad clásica europea. Con estos preceptos, el cronista indígena chalca esgrimió argumentos que pudieran asegurar a estos cristianos nuevos, y a sus ascendentes, un lugar en la salvación de la cristiandad, y a su vez sostener su privilegio en la compleja políti- 
ca mundana, quizá razón más urgente y más provechosa en su conflictiva realidad novohispana.

\section{BIBLIOGRAFÍA}

Alvarado Tezozómoc, Hernando de, Crónica mexicana, Gonzalo Díaz Migoyo y Germán Vázquez Chamorro (ed.), Madrid, Historia 16, 1997.

Chimalpáhin, Domingo, Las ocho relaciones y el memorial de Colhuacan, 2 vol., Rafael Tena (ed.), México, Consejo Nacional para la Cultura y las Artes, 1998.

Chimalpáhin, Diario, Rafael Tena (ed.), México, Consejo Nacional para la Cultura y las Artes, 2001.

Chimalpahin Cuauhtlehuanitzin, Domingo Francisco de San Antón Muñón, Octava relación. Obra histórica, José Rubén Romero Galván (ed.), México, Universidad Nacional Autónoma de México, Instituto de Investigaciones Históricas, 1983.

Chimalpahin Cuauhtlehuanitzin, Domingo Francisco de San Antón Muñón, Primer amoxtli libro. $3^{a}$ Relación de las Différentes Histoires Originales, Víctor M. Castillo Farreras (ed.), México, Universidad Nacional Autónoma de México, Instituto de Investigaciones Históricas, 1997.

Chimalpahin Cuauhtlehuanitzin, Domingo Francisco de San Antón Muñón, Séptima relación de las Différentes Histoires Originales, Josefina García Quintana (ed.), México, Universidad Nacional Autónoma de México, Instituto de Investigaciones Históricas, 2003.

Chimalpahin Quauhtlehuanitzin, Domingo de San Antón Muñón, Annals of His Time. Don Domingo de San Antón Muñón Chimalpahin Quauhtlehuanitzin, edited and translated by James Lockhart, Susan Schroeder and Doris Namala, Stanford, Stanford University Press, 2006.

Durand-Forest, Jacqueline de, "Los grupos chalcas y sus divinidades según Chimalpahin”, José Rubén Romero (trad.), Estudios de Cultura Náhuatl, vol. 11, 1974, pp. 37-44.

Durand-Forest, Jacqueline de, "Extractos de la Primera Relación de Chimalpahin Quauhtlehuanitzin (Manuscrito $N^{\circ} 74$ de la Colección Goupil-Aubin de la Biblioteca Nacional de París, folios 1 a 8 verso)", Estudios de Cultura Náhuatl, vol. 20, 1990, pp. 65-76.

Durand-Forest, Jacqueline de, L'histoire de la vallée de Mexico selon Chimalpahin Quauhtlehuanitzin (du XI au XVI siecle), Paris, L'Hartmattan, 1987.

García Cubas, Antonio, El libro de mis recuerdos: narraciones históricas, anecdóticas y costumbres mexicanas anteriores al actual estado social, ilustradas con más de trescientos fotograbados, México, Manuel León Sánchez, 1934.

Garibay, Ángel María, Historia de la literatura náhuatl, México, Porrúa, 1992. 
Gerhard, Peter, Geografía histórica de la Nueva España 1519-1821, México, Universidad Nacional Autónoma de México, 2001.

Gruzinski, Serge, Las cuatro partes del mundo. Historia de una mundialización, México, Fondo de Cultura Económica, 2010.

Ixtlilxóchitl, Fernando de Alva, Obras históricas. Incluyen el texto completo de las llamadas Relaciones e Historia de la nación chichimeca en una nueva versión establecida con el cotejo de los manuscritos más antiguos que se conocen, Edmundo O'Gorman (ed.), México, Universidad Nacional Autónoma de México, Instituto de Investigaciones Históricas, 1985.

Jalpa Flores, Tomás, Tierra y sociedad. La apropiación del suelo en la región de Chalco durante los siglos XV-XVIII, México, Instituto Nacional de Antropología e Historia, 2008.

Jarquín, Teresa y Carlos Herrejón, Breve historia del Estado de México. Disponible en: $<$ http://bibliotecadigital.ilce.edu.mx/sites/estados/libros/edomex $/ \mathrm{html} / \mathrm{sec}$ 16.html>, consultado el 10 de marzo de 2019.

Kruell, Gabriel Kenrick, "La Crónica mexicáyotl: versiones coloniales de una tradición histórica mexica tenochca", Estudios de Cultura Náhuatl, vol. 45, 2013, pp. 197-232.

Laval, Enrique, "Sobre las epidemias del fuego de San Antonio", Revista chilena de infectología, vol. 21, núm. 1, 2004, pp. 74-76.

Martínez Baracs, Rodrigo, "El diario de Chimalpáhin”, Estudios de Cultura Náhuatl, vol. 38, 2007, pp. 283-312.

Marroquí, José María, La ciudad de México, vol. I, México, Jesús Medina, 1969.

Orozco y Berra, Manuel, Apuntes para la historia de la geografía en México, México, Imprenta Escalante, 1856.

Ricard, Robert, La conquista espiritual de México. Ensayo sobre el apostolado y los métodos misioneros de las órdenes mendicantes en la Nueva España de 1523-24 a 1572, México, Fondo de Cultura Económica, 2017.

Rivera Cambas, Manuel, México pintoresco, artístico y monumental, vol. I, México, Imprenta de la Reforma, 1882.

Romero Galván, José Rubén, “Chimalpahin Cuauhtlehuanitzin”, José Rubén Romero Galván (coord.), Historiografia mexicana, vol. I, Historiografía novohispana de tradición indígena, coord. gral. de Juan A. Ortega y Medina y Rosa Camelo, México, Universidad Nacional Autónoma de México, Instituto de Investigaciones Históricas, 2003, pp. 331-350.

Romero Galván, José Rubén, "Prólogo", Susan Schroeder, David Tavárez-Bermúdez y Cristian Roa-de-la-Carrera, Chimalpáhin y La Conquista de México. La crónica de Francisco López de Gómara comentada por el historiador nahua, Universidad Nacional Autónoma de México, Instituto de Investigaciones Históricas, México, 2012, pp. 11-26.

Romero Galván, José Rubén (coord.), Historiografia mexicana, vol. I, Historiografía novohispana de tradición indígena, coord. gral. de Juan A. Ortega y Medina 
y Rosa Camelo, México, Universidad Nacional Autónoma de México, Instituto de Investigaciones Históricas, 2003.

Rovira Morgado, Rossend, "Barrios indígenas virreinales como espacios de salvaguardia y legitimación franciscanas", Latinoamérica. Revista de Estudios Latinoamericanos, núm. 62. Disponible $<$ http://www.revistadeestlat.unam.mx/index.php/latino/article/view/53294/49 924>, consultado el 10 de marzo de 2019.

Schroeder, Susan, Chimalpahin y los reinos de Chalco, trad. de Francisco Zaballa Omaña, Toluca, El Colegio Mexiquense-Honorable Ayuntamiento Constitucional de Chalco, 1994.

Schroeder, Susan, Tlacaelel Remembered. Mistermind of the Aztec Empire, Norman, University of Oklahoma Press, 2016.

Schroeder, Susan, "Introduction”, Códex Chimalpahin. Society and Politics in Mexico Tenochtitlan, Tlatelolco, Texcoco, Culhuacan, and other nahua altepetl in central Mexico, Norman, University of Oklahoma Press, 1997, pp. 3-16. 